\title{
Porcelain aorta with critical left main disease and severe aortic stenosis in a patient with heterozygous familial hyperlipidaemia presenting with cardiogenic shock
}

\author{
Apurva Vasavada, Pritesh Parekh, Navin Agrawal, Mitesh Chauhan
}

Department of Cardiology, Care Hospital, Surat, Gujarat, India

\section{Correspondence to} Dr Navin Agrawal, drnavinagrawal@gmail.com
CrossMark

To cite: Vasavada $A$, Parekh P, Agrawal N, et al. BMJ Case Rep Published online: [please include Day Month Year] doi:10.1136/ bcr-2013-201935

\section{DESCRIPTION}

Porcelain aorta is seldom seen in routine clinical practice and forms an interesting fluoroscopic image. The association of porcelain aorta with familial hyperlipidaemia, calcific left main ostial stenosis along with severe aortic valvular stenosis is a difficult combination to manage and the challenge increases in the presence of an acute infarct or in a haemodynamically compromised patient. This combination of diseases and the challenges posed in management has not been previously discussed.

We report the case of a 65 -year-old woman who was previously diagnosed with heterozygous familial hyperlipidaemia (type IIa hyperlipoproteinaemia) and had been put on high-dose statins. She was admitted for a diagnostic angiogram for a progressively worsening angina since the last 2 months (presently in Canadian Cardiovascular Society (CCS) class IV). The patient was diagnosed with critical left main coronary artery (LMCA) disease which was extensively calcified along with severe aortic valvular stenosis (videos 1-3 and figures 1$3)$.

The patient was offered the options of an elective rota-ablation assisted angioplasty to the LMCA or a coronary artery bypass grafting along with an

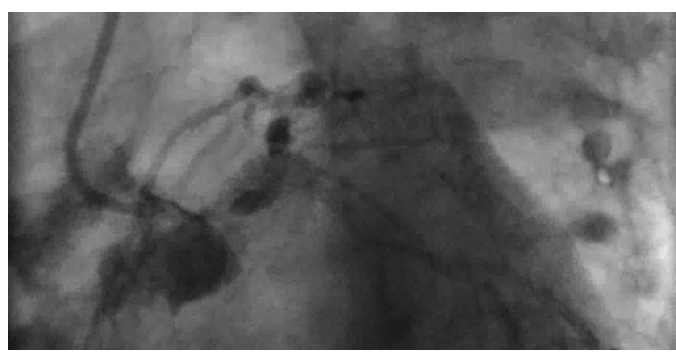

Video 1 Coronary angiogram in LAO caudal view showing critical left main stenosis.

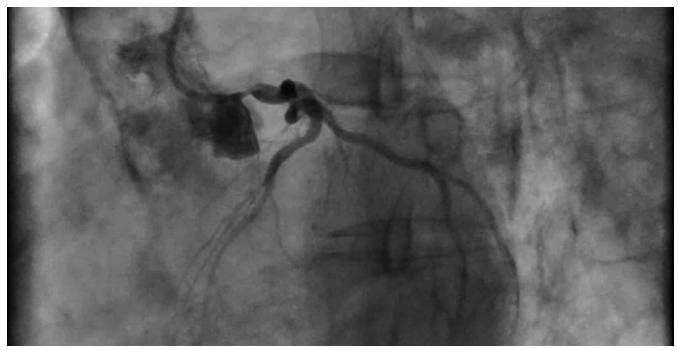

Video 2 Coronary angiogram in RAO cranial view showing critical left main disease.

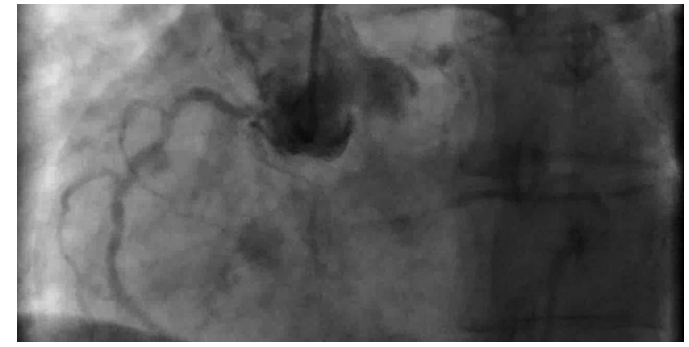

Video 3 Coronary angiogram showing porcelain aortal along with calcified right coronary artery.

aortic valve replacement. Surgery was kept at a higher priority as the patient also required an aortic valve replacement. But with the patient on high dose dual antiplatelet and anticoagulants for the management of unstable angina, an immediate surgery posed a high risk in view of the risk of uncontrollable bleeding. The presence of an extensively calcified aorta was very likely to cause difficulty in grafting and also would have increased the risk of embolisation. ${ }^{1-3}$ On the other hand rota-ablation was extremely difficult in this case with critical ostial LMCA disease in the presence of a calcified aorta. During the diagnostic angiogram we had experienced great difficulty in cannulating the artery which led us to anticipate problems in obtaining adequate guide catheter stability which is extremely important during rota-ablation.

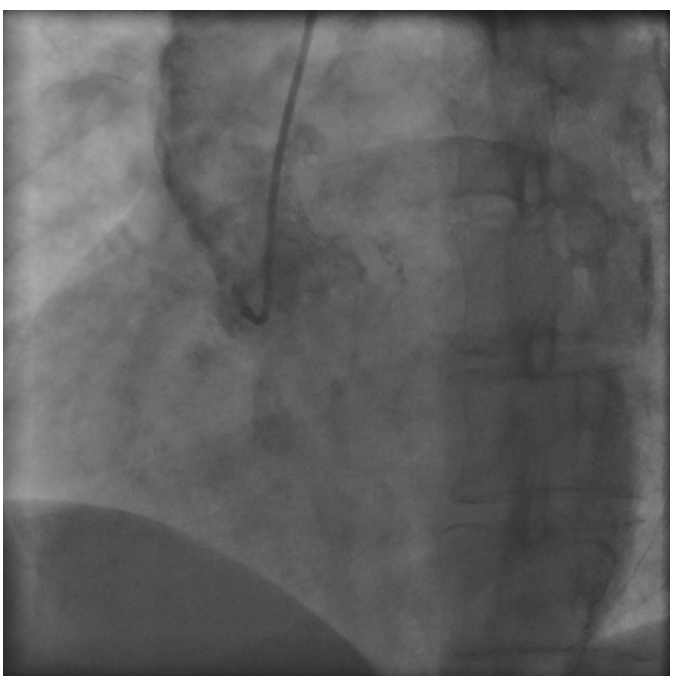

Figure 1 Calcified aorta seen in fluoroscopy along with a right coronary artery shoot showing calcification. 


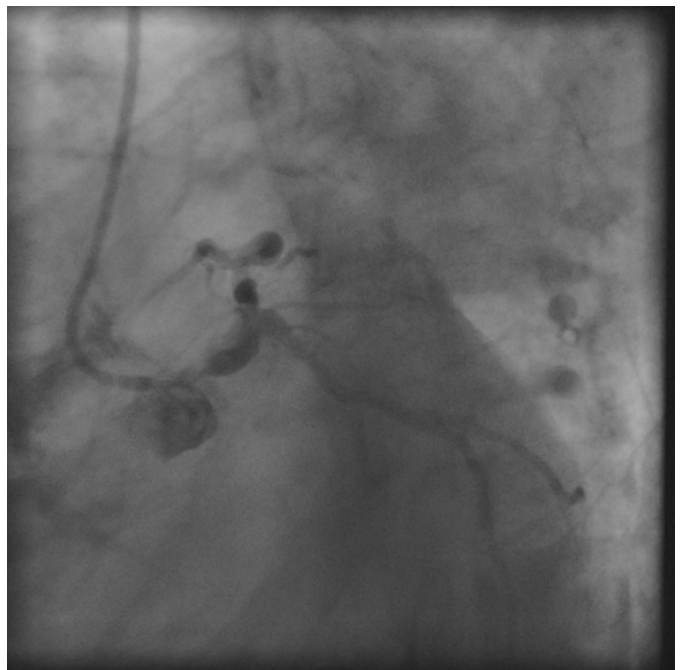

Figure 2 Left system angiogram in left anterior oblique caudal view showing critical left main stenosis along with grossly calcified aorta.

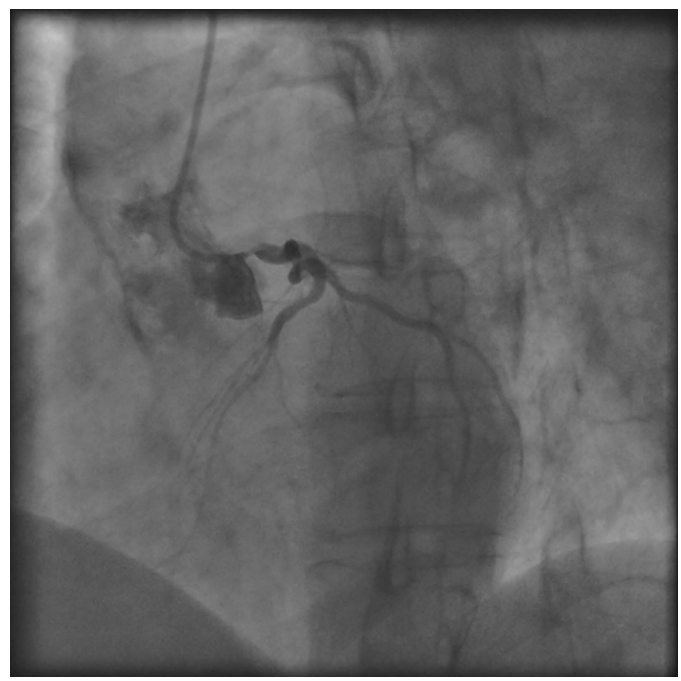

Figure 3 Left coronary artery angiographic shoot in right anterior oblique cranial shoot showing critical left main disease.

The patient unfortunately had an acute infarct on the same evening of the angiography (figure 4) involving the left main artery and developed cardiogenic shock. The patient was subsequently planned for an emergency bypass surgery but the patient died before revascularisation could actually be performed.

Familial hyperlipidaemia is an uncommon disorder with the potential to cause difficult to manage complications such as porcelain aorta, critical coronary ostial stenosis and calcific aortic stenosis which can be potentially disastrous and technically challenging when seen in combination.

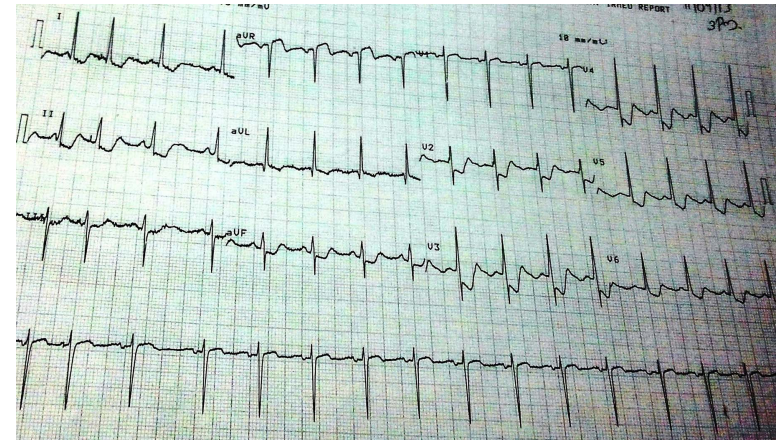

Figure 4 ECG of the patient after having the acute infract involving the left main artery showing ST elevation in aVR lead with diffuse ST depression involving multiple other leads.

\section{Learning points}

- The case is an important opportunity to understand the complications of porcelain aorta which can be associated with familial hyperlipidaemia which could make management of coronary artery disease extremely difficult especially in the case of ostial stenosis.

- Rota-ablation is extremely difficult in cases with ostial left main coronary artery disease in the presence of porcelain aorta although it can be a feasible option in experienced hands but the rate of complications is high and chances of technical success is less.

- Coronary artery bypass grafting techniques that do not require cross-clamping, partial clamping or manipulation of the aorta, avoiding cardiopulmonary bypass,' no-touch' technique and placing proximal anastomoses on one of the branches of the aortic arch are useful management tips in such patients undergoing surgery although the rate of complications are high.

Competing interests None.

Patient consent Obtained.

Provenance and peer review Not commissioned; externally peer reviewed.

\section{REFERENCES}

1 Peigh PS, DiSesa VJ, Collins JJ Jr, et al. Coronary bypass grafting with totally calcified or acutely dissected ascending aorta. Ann Thorac Surg 1991;51:102-4.

2 Demirsoy $E$, Unal $M$, Arbatlı $H$, et al. Extra-anatomic coronary artery bypass graftings in patients with porcelain aorta. J Cardiovasc Surg (Torino) 2004;45:111-15

3 Leyh RG, Bartels C, Nötzold A, et al. Management of porcelain aorta during coronary artery bypass grafting. Ann Thorac Surg 1999;67:986-8. 
Copyright 2013 BMJ Publishing Group. All rights reserved. For permission to reuse any of this content visit http://group.bmj.com/group/rights-licensing/permissions.

BMJ Case Report Fellows may re-use this article for personal use and teaching without any further permission.

Become a Fellow of BMJ Case Reports today and you can:

- Submit as many cases as you like

- Enjoy fast sympathetic peer review and rapid publication of accepted articles

- Access all the published articles

- Re-use any of the published material for personal use and teaching without further permission

For information on Institutional Fellowships contact consortiasales@bmjgroup.com

Visit casereports.bmj.com for more articles like this and to become a Fellow 